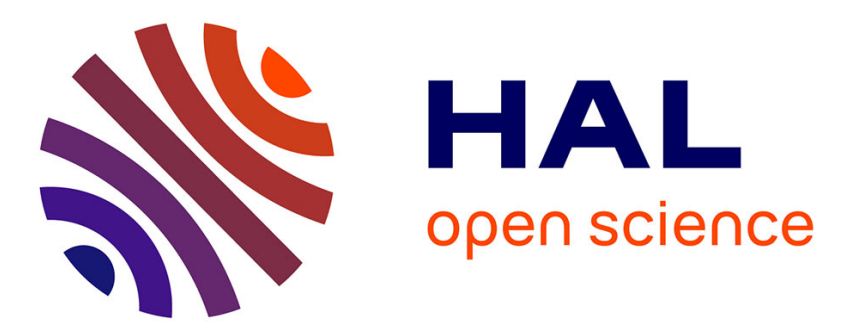

\title{
Feasibility of Wireless Gas Detection with an FMCW RADAR Interrogation of Passive RF Gas Sensor
}

Hamida Hallil, Franck Chebila, Philippe Menini, Patrick Pons, Hervé Aubert

\section{To cite this version:}

Hamida Hallil, Franck Chebila, Philippe Menini, Patrick Pons, Hervé Aubert. Feasibility of Wireless Gas Detection with an FMCW RADAR Interrogation of Passive RF Gas Sensor. IEEE Sensors 2010, Nov 2010, Hawaii, United States. pp.759 - 762, 10.1109/ICSENS.2010.5690765 hal-00672682

\section{HAL Id: hal-00672682 https://hal.science/hal-00672682}

Submitted on 20 Jun 2019

HAL is a multi-disciplinary open access archive for the deposit and dissemination of scientific research documents, whether they are published or not. The documents may come from teaching and research institutions in France or abroad, or from public or private research centers.
L'archive ouverte pluridisciplinaire HAL, est destinée au dépôt et à la diffusion de documents scientifiques de niveau recherche, publiés ou non, émanant des établissements d'enseignement et de recherche français ou étrangers, des laboratoires publics ou privés. 


\title{
Feasibility of Wireless Gas Detection with An FMCW RADAR Interrogation of Passive RF Gas Sensor
}

\author{
Hamida Hallil $^{*+}$, Franck Chebila ${ }^{*+}$, Philippe Menini ${ }^{*+}$, Patrick Pons ${ }^{*}$, Hervé Aubert ${ }^{*+}$ \\ ${ }^{*}$ CNRS ; LAAS ; 7 Avenue du Colonel Roche, F-31077 Toulouse, France \\ + Université de Toulouse ; UPS, INP ; LAAS ; F- 31077 Toulouse, France \\ hhallil@laas.fr
}

\section{Summary}

The feasibility of the remote measurement of gas detection from an RF gas sensor has been experimentally investigated. It consists of a Frequency-Modulated Continuous-Wave (FMCW) RADAR interrogation of an antenna loaded by the passive sensor. The frequency band of the RADAR [28.8$31 \mathrm{GHz}$ ] allows the detection of the resonant frequencies of Whispering Gallery Modes that are sensitive to gas concentration. Reported experimental results provide the proof-of-concept of remote measurement of gas concentration fluctuation from RADAR interrogation of this new generation of passive gas sensors.

\section{Motivation}

Recent results obtained from electromagnetic simulations ${ }^{1}$ indicated that a $\mathrm{TiO}_{2}$ dielectric resonator (DR) can adsorb gas molecules (like CO) and such adsorption induces a frequency shift in resonant frequencies of high-sensitive Whispering Gallery (WG) modes .This transduction is given by the dielectric relaxation effect at high frequency. The experimental validation of the design and electromagnetic simulations was carried out using BaSmTiOxide ceramic as a dielectric material for the DR instead of $\mathrm{TiO}_{2}$, as it is easier to fabricate by standard Sintering technique than metal oxide DR: the dielectric property of this ceramic presents a relative permittivity $\left(78.6 \pm 2\right.$ from $\left.^{2}\right)$ is very close to $\mathrm{TiO}_{2}$ one.

\section{Results}

The fabricated Whispering-Gallery mode resonator with its coplanar waveguide (CPW) feeding lines is shown in Fig.1. The measured transmission coefficient $S_{13}$ in the millimeter-wave frequency range is reported in Fig. 2. As expected, transmission peaks are observed at the resonant frequency of the $\mathrm{WGH}_{5,0,0}$ , $\mathrm{WGH}_{6,0,0}$ and $\mathrm{WGH}_{7,0,0}$ modes. Due to the technological inaccuracies, the three resonators (with the same dimensions) micro-machined on the same wafer do not have identical transmission peak magnitudes and frequencies : for example the $\mathrm{WGH}_{7,0,0}$ mode resonates at $29.4 \mathrm{GHz}$ for the resonator 1 , at $29.5 \mathrm{GHz}$ for the resonator 2 and at $29.9 \mathrm{GHz}$ for the resonator 3 (see fig.3). These three resonators can be considered as a gas sensor that resonates at three different frequencies, each frequency corresponding to a specific gas concentration. These three resonant frequencies (or gas concentration) can be measured from the FMCW RADAR interrogation of an antenna loaded by the resonator (passive sensor). As shown in Fig.4, the sensor interrogated by this reader, use an identification technique ${ }^{3}$ which depends on the backscattered signal of the horn antenna (structural mode) and the cables delay line, a length of coaxial cable, connected to the cell (antenna mode). The three $\mathrm{WGH}_{7,0,0}$ resonant frequencies can be scanned by the RADAR because they belong to its specific band $(28.8 \mathrm{GHz}$ to $31 \mathrm{GHz})$. In the FMCW radar output spectrum, the beat frequency that allows measuring the location of the sensor can easily be detected (here the distance between the radar antenna and the sensor horn antenna is $3.4 \mathrm{~m}$ and consequently the beat frequency is $30 \mathrm{KHz}$ ). Depending on load which is applied to its output, on Fig.5, the presence or absence of the sensor is checked. Table 1 shows the variation of radar amplitude between the three structures with the output open circuit. These first measures validate the feasibility of a radar measurement of gas detection and their quantity by wireless communication between the reader and a totally passive sensor.

${ }^{1}$ H. Hallil, P. Ménini, H. Aubert, "Novel Millimeter-Wave Gas Sensor Using Dielectric Resonator with $\mathrm{TiO}_{2}$ sensitive layer”, IEEE Sensors Conference, New Zealand, 25-28 October, 2009.

2 TEMEX CERAMICS (http://www.temex-ceramics.com).

${ }^{3}$ F. Chebila, M. M. Jatlaoui, P. Pons and H. Aubert, "Pressure Measurement from the RADAR Interrogation of Passive Sensors", accepted in IEEE symposium Antennas and Propagation Society, Canada July 11-17, 2010 
Figures

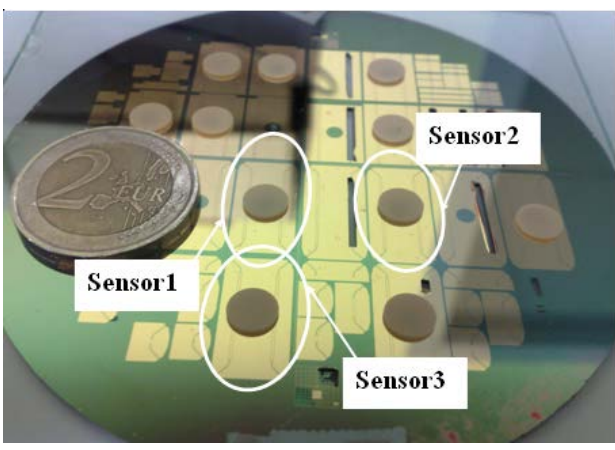

Fig. 1: Fabricated sensors on 4" Silicon wafer: resonator with its CPW excitation lines.

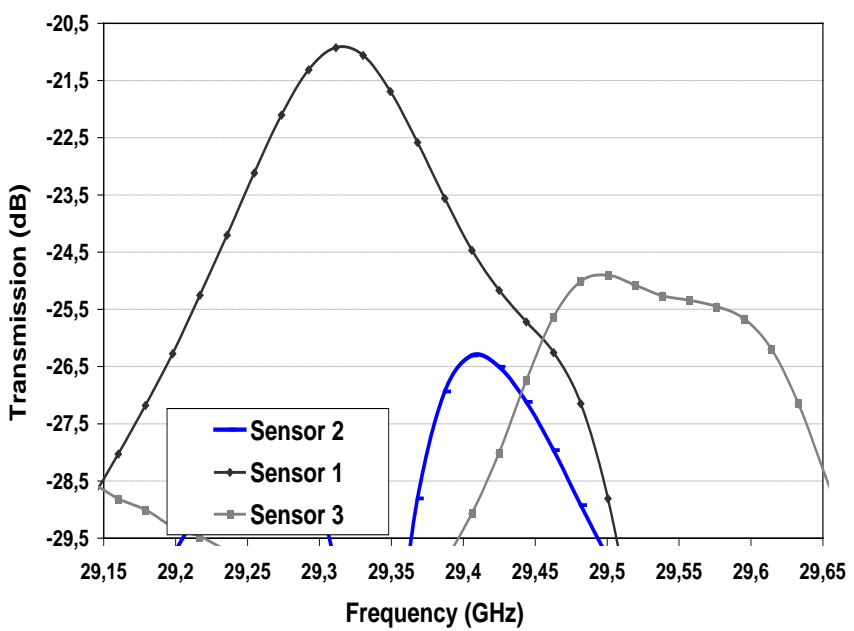

Fig. 3: Measured transmission coefficient versus frequency for three sensors at $\mathrm{WGH}_{7,0,0}$.

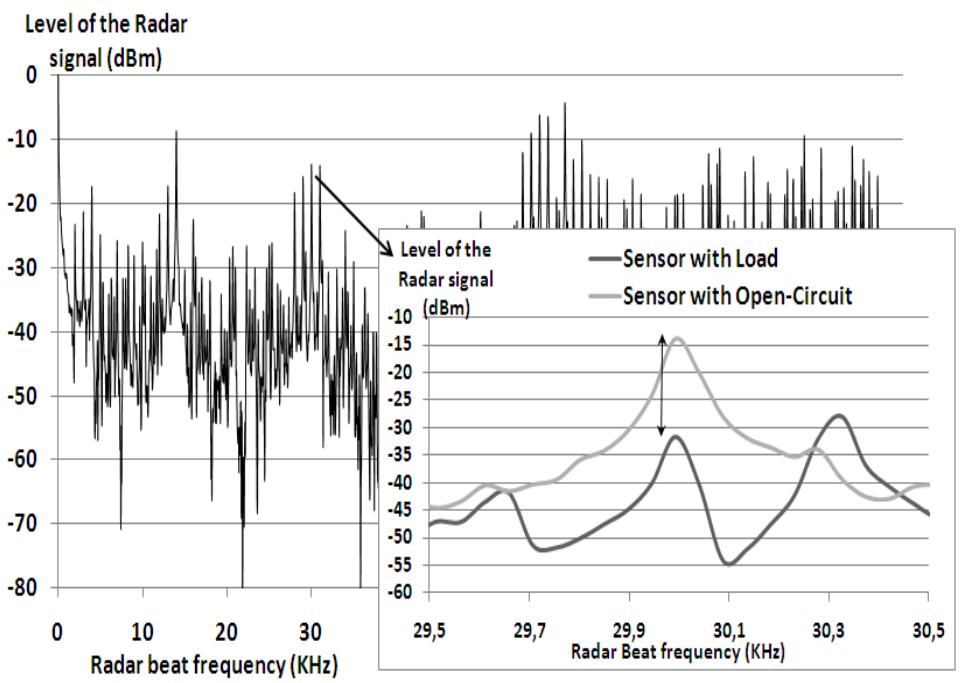

Fig. 5: Spectrum of the radar signal: Identification of the sensor variations (with and with out load)

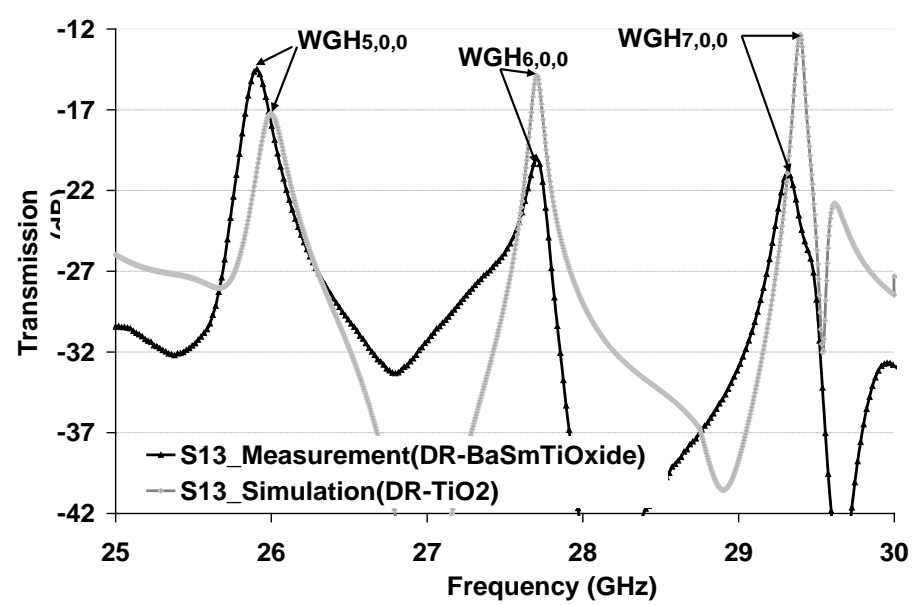

Fig. 2: Measured and simulated transmission coefficients versus frequency for the $\mathrm{BaSmTiOxide}$ and $\mathrm{TiO}_{2}$ dielectric resonator.

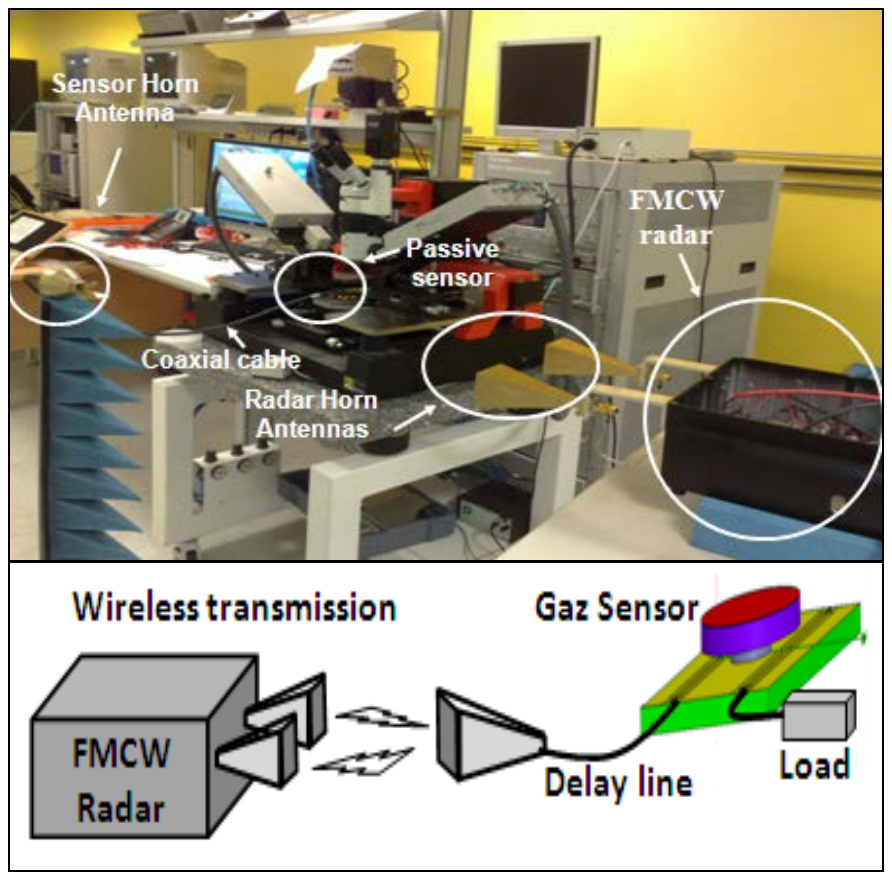

Fig. 4: Experimental assembly between the radar and gas sensor

\begin{tabular}{|l|c|c|c|}
\hline \multicolumn{1}{|c|}{ Level of the Radar signal } & Sensor 1 & Sensor 2 & Sensor 3 \\
\hline Sensor with open-circuit (dBm) & $-10,4$ & $-12,7$ & $-13,9$ \\
\hline Sensor with Load (dBm) & -43 & $-18,5$ & $-31,7$ \\
\hline
\end{tabular}

Table 1: Level of the beat frequency radar for each sensor $(1,2$, and 3$)$ 